\title{
Assessment of Knowledge, Attitude and Practices on Reproductive Health Among Ambo University Students in Ambo, Oromia National Regional State, Ethiopia, 2013/14
}

\author{
Mitsiwat Abebe Gebremichael, Eshetu Ejeta Chaka \\ Department of Nursing, College of Medicine and Health Sciences, Ambo University, Ambo, Ethiopia
}

Email address:

mitseabe@gmail.com (M. A. Gebremichael),eejta@yahoo.com (E. E. Chaka)

To cite this article:

Mitsiwat Abebe Gebremichael, Eshetu Ejeta Chaka. Assessment of Knowledge, Attitude and Practices on Reproductive Health Among Ambo University Students in Ambo, Oromia National Regional State, Ethiopia, 2013/14. Science Journal of Public Health.

Vol. 3, No. 2, 2015, pp. 222-228. doi: 10.11648/j.sjph.20150302.20

\begin{abstract}
Introduction: Adolescent's sexuality and Reproductive Health are generally not well addressed to protect them from unwanted pregnancies, complications of unsafe abortions and sexual transmitted infection including human immunodeficiency virus/AIDS. Although the numbers of young people who need information and services are enormous, services are scarce, fragmented and nonexistent. Objective: To assess the level of Knowledge, Attitudes and Practice towards reproductive health among students of Ambo university. Methods: Institutional based descriptive cross-sectional study design supplemented by qualitative in-depth interview was conducted among Ambo University students, Ambo, western Ethiopia from December to January 2013/14. Multistage sampling technique was implemented and sample size taken was 605. Data were collected using structured and pretested questionnaires and entered into EPI Info 3.5.1 then exported to SPSS Version 16 for analysis. Result: Respondent were mentioned different methods to prevent reproductive health problem, and from these 111(18.5\%) mentioned condom, 44 (7.9\%) Abstain as the method of choice while 322(53.7\%) mentioned that they didn't know prevention methods. From the total students participated in the study $487(81.2 \%)$ have shown interest to use reproductive health service in the future and 350(84.7\%) of the respondents wanted the establishment of reproductive health services within the university campus. $108(42 \%)$ of the respondents were started sex before the age of 18 years and only $6(2.4 \%)$ of the students were start sex after 24 years. 179(73.5\%) of the students were not using contraceptive during the survey period Conclusion: the study showed that most the respondent didn't know reproductive health components, problems and as well didn't mention prevention methods. A great number of students were not used reproductive health services during the survey period; but there will be high demand to utilize reproductive health services. Recommendation: Since there was high demand on reproductive health services; Policy Makers(Program planners) should establish friendly reproductive health services within the university to increase coverage and prevent the students from reproductive health related problems and complications.
\end{abstract}

Keywords: Reproductive Health, Knowledge, Attitude and Practice

\section{Introduction}

Reproductive health (RH) is defined as" A state of complete physical, mental, and social wellbeing and not merely the absence of disease or infirmity, in all matters related to the reproductive system and to its functions and process". It addresses the human sexuality and reproductive processes, functions and system at all stages of life and implies that people are able to have "a responsible, satisfying and safe sex life and that they have the capability to reproduce and the freedom to decide if, when and how often to do so(1)
Youth Reproductive Health (YRH) is a relatively new area of health intervention in most of developing countries. Adolescents face various obstacles in accessing the services, one of which is receiving accurate information regarding reproductive and sexual health. In addition, adolescents are often not aware of adolescent-friendly sources of care, which when combined with their limited knowledge hinders their ability to make informed choices to protect and promote their own well-being(2).

Adolescents/youth are the forgotten millions in Reproductive Health Programs. Adolescent's sexuality and Reproductive Health are generally not well addressed to 
protect them from unwanted pregnancies, complications of unsafe abortions and Sexually transmitted infections(STIs) including HIV/AIDS. Although the numbers of young people who need information and services are enormous, services are scarce, fragmented and nonexistent(3).

Adolescents obtain information and make decisions within the context of the culture in which they live. Decisions and actions may be affected by Violence, Drug, Alcohol use, School attendance; Work, Economic opportunities, Self image and Autonomy in decision-making(2) Adolescent's needs are often misunderstood, unrecognized or underestimated(3)

Today approximately one-fifth of the world's population is adolescents and young adults, with more than four fifths in developing countries $(3,4)$. During the transition from childhood to adulthood, adolescents establish patterns of behavior and make lifestyle choices that affect both their current and future health. Sexual activity among adolescent has been reported to be on the increasing worldwide. Most young people throughout world will engage in sexual intercourse by age 20 , whether married or unmarried $(4,5)$.

Adolescence is a challenging phase of life, within which the individual attains physical, sexual and social maturity. Studies done in Northern Ghana shows being an adolescent is especially challenging: the youth is mostly left alone to face the HIV/AIDS epidemic, the risks of sexually transmitted illnesses (STIs), unwanted pregnancies and unsafe illegal abortions. Furthermore, sexual violence is becoming increasingly prevalent(6).

Studies show that for many adolescent girls the first sexual experience is coercive and that physical abuse and violence are significant parts of young women lives. In many cases sexual coercion and violence start in childhood and adolescence(7).

A study done among youths in Harar, Ethiopia revealed that the highest proportion, $48.1 \%$ of males and $37.8 \%$ of females, had their first sexual encounter at 15-17 years of age About one third of the respondents had their first experience of sexual intercourse at ages of 18-19 and only $13.6 \%$ above the age of 20 years. The mean age at first sexual exposure among unmarried youths was 17.2 years (16.9 and 18 years for males and females respectively(8)

Most sexually active adolescents do not use modern contraception. Common reasons for non use: according to the study done in Nekemte, Ethiopia were; Did not expect to have sex, Lack of information about contraceptives and Lack of access to contraceptives(9).

Youth constitute a large proportion of the population in developing countries and are disproportionately affected by HIV/AIDS and others negative reproductive health out come. The existing literatures document that adolescents engage in premarital sex with insufficient knowledge of reproductive health and family planning, and the small proportion use contraceptive, especially condom (10).

Pregnancies occurring among unmarried women are often unintended(2). Unintended pregnancies result from contraceptive non-use, misuse, and method failure.
Adolescent women are more likely not to use and to misuse contraceptive than older women(11).

Sexual health of young people is a matter of public health concern and Reproductive health occupies a central position in health and development (12).

\section{Significance of the Study}

Reproductive health problems like Abortion, risky sexual practice, unwanted pregnancy, Sexually Transmitted Infection/ Sexually Transmitted Diseases (STI/STD) and sexual violence are common among institutional population/students and similar study did not conducted previously to present the magnitude of the problem.

Therefore, this assessment is believed to give the present image of reproductive health related issue of the students with in the study area, which may help the concerned bodies to take actions based on the findings. As well the study may provide base line information for further studies that may be conducted in similar issues.

\section{Objectives}

\subsection{General Objective}

To assess the level of knowledge ,attitudes and practice towards reproductive health among students of Ambo university.

\subsection{Specific Objectives}

To determine students knowledge of reproductive health in the study area.

To find out students attitude towards reproductive health in the study area

To describe the practice of reproductive health services in the study area

To assess students demand on reproductive health services in the study area

\section{Methods and Materials}

\subsection{Study Area}

The study was carried out in Ambo University, West Shewa Zone, Oromia National Regional State, Ethiopia. Ambo University is located in Ambo which is situated only 112 west of Addis Ababa (the capital city of Ethiopia). Ambo University first established as college of Agriculture in 1939 and became Ambo University in 1999; and is one of the oldest higher learning institutions in Ethiopia. It was running 9 colleges/institutes and 38 academic departments. During the study period the University had a total of 15,841 students.

\subsection{Study Design and Period}

Institutional based descriptive cross-sectional study design was conducted among Ambo University students from December to January 2013/14. 


\subsection{Source Population}

All students in Ambo University from December to January 2013/14.

\subsection{Study Population}

All students who are randomly selected from each college/Institute in the University during December to January 2013/14.

\subsection{Sample Size and Sampling Technique}

\subsubsection{Sample Size Determination}

The sample size was calculated using a single proportion formula. Assuming the proportion of students who are aware of emergency contraception to be $50 \%$, adding non-response rate of $5 \%$, and multiplying by a design effect of 1.5 due to the multistage nature of the sampling method the required sample was 605 based on proportional allocation.

At the first 19 departments was selected using probabilitysampling proportion to size method from a total of 38 departments at Ambo university (from nine colleges/ Institute/school). Then individual students were selected using simple random sampling method from the selected departments

\subsubsection{Sampling Procedures}

Multistage sampling technique was implemented. After calculating the sample size, all colleges and year of study were considered in the sampling process for the selection of the study subjects. Total university undergraduate regular students were stratified in to colleges and the sample was distributed to each colleges using probability proportional to their size. Secondly using Simple Random Sampling (SRS) 19 departments from the nine colleges were identified. The required numbers of undergraduate regular students (sample size) were distributed to each year of study and department again using probability proportional to size. The study subjects were selected from each selected department among all year of study in the department using simple random sampling technique. Programmes were arranged with the department heads and teachers. The questionnaires were distributed to and collected from the study subjects before/after class started.

\subsection{Variables of Study}

\subsubsection{Dependent Variables}

- Knowledge of RH

- Attitude of students to ward RH

- Practice on RH

\subsubsection{Independent Variables}

- Socio-demographical factors: age, Sex, year of study, Residence

- Socio economic factors: income, access to radio,

- Sexual Related issues(Ever had sexual practice, Use condom, no of sexual partner, absence/presence of boy/girl friend, Age at which start of sex)
- History of abortion

- Accessibility of reproductive health service

- Past and current use of RH service

- Demand of reproductive health service

\subsection{Operational Definitions}

Knowledge: is awareness and understanding that one has gained on reproductive health issues through learning and practice and respondents was considered to be knowledgeable if he/(s) correctly answered greater than or equal to $70 \%$ of the total knowledge assessing questions

Attitude - The way of thinking to which RH should be provided to and an intention to use $\mathrm{RH}$ services in the future

Practice -Utilization of at least any Reproductive health services

\subsection{Data Collection Tools and Procedures}

Data was collected using self-administered questionnaires. The questionnaires was prepared in English and was pretested in students at two departments of wollega university, Western Ethiopia, other than the study area, one week before the start of data collection. Five data collection facilitators were trained and involved in data collection.

\subsection{Data Processing and Analysis}

Data processing and analysis was done using the SPSS version 16 for windows program. Descriptive statistics Such as frequencies, percentage, appropriate graphic presentation besides measures of central tendency and measures of dispersion used for Univariate analysis. Bivariate analysis was made for some variables.

\subsection{Data Quality Assurance}

To assure data quality, pre-tested collection tools (questionnaire) was prepared in English and translated into Amharic, data collectors and the supervisor were trained on the data collection techniques. In addition, the completeness, accuracy and consistency of the collected data were checked on daily basis during the data collection time, by the principal investigator and trained supervisor. Supervisors \& principal investigator closely follow the data collection process. Double data entry were done by the principal investigator to keep accuracy of the data. The collected data coded and cleaned then entered into SPSS version 16.

\subsection{Ethical Considerations}

The study was carried out after getting permission from the ethical review committee of Ambo University. A letter of support which indicates the objective of the study was written to each College, from Ambo University Research Director. The purpose and importance of the study was explained to the participants. Data were collected after full informed verbal consent was obtained and confidentiality of the information was also maintained by omitting their names and personal identification or privacy. 


\subsection{Dissemination of Results}

The final report will be submitted to Ambo University research board, Ambo town health department and present on different conference. Also the results will be disseminated through Publication in local or international journals.

\section{Result}

Table 1. Socio-demographic and academic characteristics among Ambo university students; Ambo, Oromia National Regional State, Ethiopia, 2013/14.

\begin{tabular}{lll}
\hline Variable & Frequency & Percent(\%) \\
\hline Sex & & \\
Male & 377 & 62.8 \\
Female & 223 & 37.2 \\
Marital status & & \\
Single & 554 & 92.3 \\
Married & 43 & 7.2 \\
Separated & 3 & 0.5 \\
Residence & & \\
Urban & 258 & 43 \\
Rural & 342 & 57 \\
Year of study & & \\
Year I & 249 & 41.5 \\
Year II & 150 & 25.0 \\
Year III & 124 & 20.7 \\
Year IV & 8 & 1.3 \\
Total & 600 & $100 \%$ \\
\hline
\end{tabular}

Full response was obtained from a total of 600 students (377 male and 223 female) making the response rate $99 \%$.
The age of study participants ranged from a minimum of 19 years to a maximum of 51 years. The mean age was $22 \pm 3.4$ years. Majority $(92.3 \%)$ of students were not married (Table 1)

Among students who were sexually active 28 (24.3\%) of them have ever had practiced abortions one or more times. This figure accounts for $11 \%$ of all the students who are sexually active.

Fear of family $(60.7 \%)$ and to continue education $(39.3 \%)$ was the main reason reported by respondents for undertaking abortion.

About 138 (23\%) of the students said that they have heard about contraceptives methods. Among those who have ever heard of contraceptives methods, 74 (53.6\%) and 20 (14.5\%) emergency contraceptive and condom mentioned respectively.

Those students who have mentioned emergency contraceptive were asked which contraceptive methods not suitable for youth to use and $193(32.2 \%)$ sterilization \& 109 $(18 \%)$ say condom.

Respondents were asked whether they know what reproductive health means and 59 (9.9\%) acknowledged that they know about it. Out of 59 they gave answers that it is sexual transmitted infection 26(4.3\%).

A considerable proportion (about 90.2\%) of the respondents, however, did not know or did not respond to the question concerning component of reproductive health. see figure 1 .

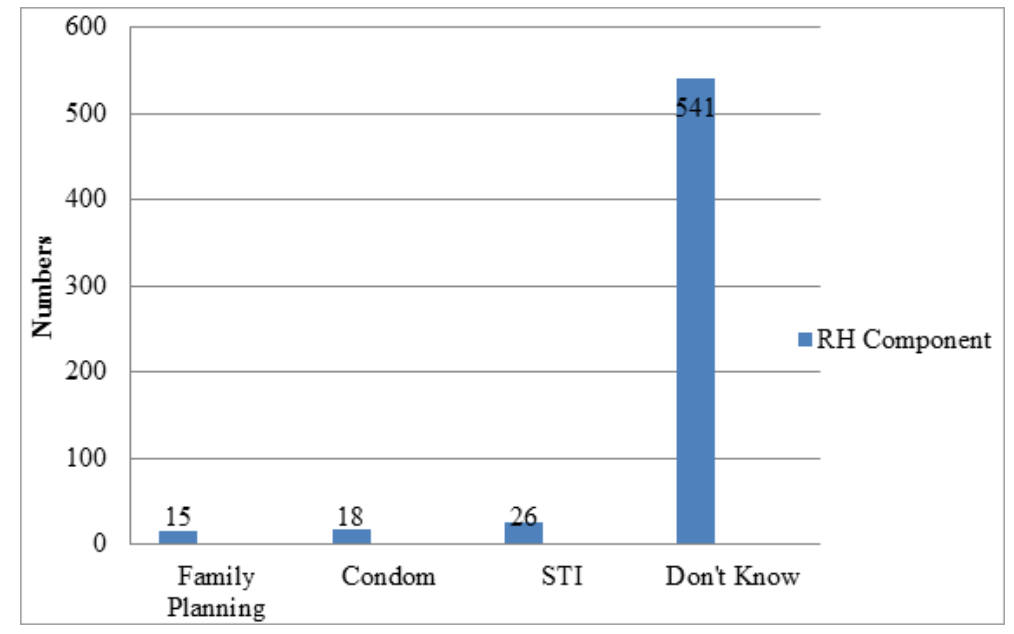

Fig. 1. Mentioned RH component amng Ambo University students, Ambo, Ethiopia 2013/14.

About $434(72.3 \%)$ of the students said that they have heard about reproductive problem, however significant number $312(71.9 \%)$ mention HIV/AIDS followed by unwanted pregnancy $96(22.2 \%)$

Open-ended question of how they can prevent reproductive health problem was asked and they mentioned 111(18.5\%) condom, $44(7.9 \%)$ Abstain as the method of choice while $322(53.7 \%)$ mentioned that they do not know prevention methods and $180(30 \%)$ of the respondents could not mention any types of sexually transmitted infection

\subsection{Demand on RH Service in the Future and Plan to Use Contraceptive Method in the Future}

Among the total students participated in the study $487(81.2 \%)$ shows need to use Reproductive health service in the future and $350(84.7 \%)$ of the respondents wants the establishment of Reproductive health services within the university campus. One hundred forty $(82.8 \%)$ will have plan to use contraceptive in the future among those not currently used. (Table 2) 
Table 2. Demand on RH services and plan to use contraceptive method in the future among Ambo University students, Ambo, Oromia National Regional State, Ethiopia, 2013/14.

\begin{tabular}{lcc}
\hline Characteristics & Number & Percent(\%) \\
\hline Need to use RH service in the future(600) & \\
Yes & 487 & 81.2 \\
No & 113 & 18.8 \\
Need of establishment of RH service among who respond service is not \\
available (413) \\
Yes & 350 & 84.7 \\
No & 63 & 15.3 \\
Plan to Use contraceptive method in the & future among not used \\
currently(169) & 140 & 82.8 \\
Yes & 29 & 17.2 \\
No & & \\
\hline
\end{tabular}

\subsection{Attitude Towards Reproductive Health Service}

Respondents strongly agree about the importance of Reproductive health services for youth. 367(61.2\%) of the students strongly agree about the importance of reproductive health services for youth. Students strongly disagree the inclination that only females should use reproductive health service. $280(46.7 \%)$ of the students were strongly disagree that only female should use reproductive health service. (Table 3)

Table 3. Attitude towards Reproductive health service among Ambo university students, Ambo, Oromia National Regional State, Ethiopia, 2013/14.

\begin{tabular}{lll}
\hline RH service Important for youth(419) & Number & Percent \\
\hline Strongly agree & 367 & $61.2 \%$ \\
Strongly disagree & 52 & $8.7 \%$ \\
Every young person should aware of RH service(362) & \\
Strongly agree & 291 & $48.5 \%$ \\
Strongly disagree & 71 & $11.8 \%$ \\
Only females should use RH service (358) & \\
Strongly agree & 78 & $13 \%$ \\
Strongly disagree & 280 & $46.7 \%$ \\
\hline
\end{tabular}

\subsection{Sexual Practice}

Two hundred fifty seven (42.8\%) ever had sexual practice in their life time (Table4)

Table 4. Ever had sexual intercourse among Ambo university students, Ambo, Oromia National Regional State, Ethiopia, 2013/14.

\begin{tabular}{lll}
\hline Ever had sexual intercourse & Frequency & Percent \\
\hline Yes & 257 & 42.8 \\
No & 335 & 55.8 \\
No response & 8 & 1.3 \\
Total & 600 & 100 \\
\hline
\end{tabular}

One hundred forty three $(55.6 \%)$ of the respondents were reported that they started sex within the age of 18-24 years.
$108(42 \%)$ were start sex before the age of 18 years and only $6(2.4 \%)$ of the students were start sex after 24 years. One hundred seventy one $(66.5 \%)$ of the respondents were practice sex before joining university and eighty six (33.5\%) were start sex after joining university.(Table 5).

Table 5. Age at which respondents start sex and time to start sex among Ambo university students, Ambo, Oromia National Regional State, Ethiopia, 2013/14.

\begin{tabular}{lll}
\hline Characteristics & Frequency & Percent(\%) \\
\hline Age at which start sex(257) & & \\
$<18$ & 108 & 42 \\
$18-24$ & 143 & 55.6 \\
$>24$ & 6 & 2.4 \\
When did you start sex(257) & & \\
Before join university & 171 & 66.5 \\
After join university & 86 & 33.5 \\
\hline
\end{tabular}

From two hundred fifty Seven respondents who had ever sexual intercourse, $179(73.5 \%)$ of the students were not using contraceptive during the survey period ( Table 6).

Table 6. Current Use of Contraceptive method among Ambo university students, Ambo, Oromia National Regional State, Ethiopia, 2013/14.

\begin{tabular}{lll}
\hline Characteristics & Frequency & Percent(\%) \\
\hline Currently use contraceptive method (257) & \\
Yes & 68 & 26.5 \\
No & 179 & 73.5 \\
\hline
\end{tabular}

From the total respondents currently using reproductive health services $59.1 \%$ were male and the rest $41.1 \%$ were females. The majorly utilized components of reproductive health by the students in the study area were Voluntary Counselling and Testing of HIV(VCT) and Condom( Table 7 and 8)

Table 7. Current Use of reproductive health service by sex among Ambo university students, Ambo, Oromia National Regional State, Ethiopia, $2013 / 14$.

\begin{tabular}{llll}
\hline Characteristics & Sex & & \multirow{2}{*}{ Total } \\
\cline { 1 - 2 } $\begin{array}{llll}\text { Current use of reproductive } \\
\text { health service }\end{array}$ & Male & Female & \\
\hline Yes & $165(59.1)$ & $115(41.2)$ & 279 \\
No & $174(69.3)$ & $77(30.7)$ & 251 \\
\hline
\end{tabular}

Table 8. Type of reproductive health service utilized among Ambo university students, Ambo, Oromia National Regional State, Ethiopia, 2013/14.

\begin{tabular}{lll}
\hline $\begin{array}{l}\text { The type of service Taken } \\
\text { currrently(279) }\end{array}$ & Number & Percent \\
\hline VCT & 132 & 47.3 \\
Condom & 106 & 38 \\
IEC & 24 & 8.6 \\
Other Contraceptives & 17 & 6.1 \\
Total & 279 & 100 \\
\hline
\end{tabular}


The survey try to show show reproductive health service utilization by the year of study, forth year students were highly utilizing $(62.5 \%)$ than the other and followed by third year students $(59.7 \%)$, second year $(56 \%)$ and first year (47.4\%) (Table 9).

Table 9. Current Use of RH service by year of study among Ambo university students, Ambo, Oromia National Regional State, Ethiopia, 2013/14.

\begin{tabular}{llll}
\hline Year of & \multicolumn{3}{l}{ Currently using the service } \\
\cline { 2 - 4 } Study(279) & Yes N(\%) & No N(\%) & Total \\
\hline First year & $118(47.4)$ & $131(52.6)$ & 249 \\
Second year & $84(56)$ & $66(44)$ & 150 \\
Third year & $74(59.7)$ & $50(40.3)$ & 124 \\
Fourth year & $5(62.5)$ & $3(37.5)$ & 8 \\
\hline
\end{tabular}

\section{Qualitative Result}

\subsection{Demand Related to Reproductive Health Services}

The key informant(health professional) working at student clinic said " many students have high need for reproductive health services but we have only VCT services and condom provision in our clinic as a component of reproductive health services , might be as a consequence of this; a number of students encounter a number of reproductive health problem"

\subsection{Reason for not Using Reproductive Health Services}

The reason obtained from qualitative data; On why the respondent's did not utilize RH services is because it is not accessible.

One student said: "When I went to student clinic to use reproductive health services(emergency contraceptive and STI screening) only voluntary counseling and test and Condom is available, I ask them from where to get and they told me to search outside the campus" (22 years old female students)

\section{Discussion}

A considerable proportion 541(90.2\%) of the respondents didn't know the component of reproductive health, this is consistent with the study done in Ghana(14) This has great implication for not utilizing the service and to encounter reproductive health problem and or complication. Beside this a lot of students mentioned that they did not know and use youth-friendly reproductive health services

Students were asked which contraceptive methods not suitable for youth to use and 193 (32.2\%) sterilization \& 109 $(18 \%)$ say condom. This shows that there is some miss understood of condom benefit because condom is the best method recommended for youth for its dual function.

Three hundred sixty seven $(61.2 \%)$ of the students strongly agree about the importance of reproductive health services for youth. This also consise with the studies done in different parts of the world and is highly related to the importance of RH services(15). Students strongly disagree the inclination that only females should use reproductive health service. This implies that students have positive attitude that both sexes should use the services

Among students who were sexually active 28 (24.3\%) of them have ever had practiced abortions one or more times. This figure accounts for $11 \%$ of all the students who are sexually active. Even if $100 \%$ possible to prevent abortion, $11 \%$ of the students encounter the problem, this is because only VCT and Condom was provided for them, no emergency contraceptive is given or students had no awareness on it. This is also consistent with the qualitative finding

Among the total students participated in the study $487(81.2 \%)$ shows interest to use reproductive health services in the future and $350(84.7 \%)$ of the respondents wants the establishment of Reproductive health services within the university campus. This finding showed that students in the study area have high demand for reproductive health services in general and contraceptive method in particular. This finding also triangulated and consistent with Key informants working in student clinic and showed there was gaps in the component of reproductive health services

One hundred forty three $(55.6 \%)$ of the respondents were reported that they start sex within the age of 18-24 years. $108(42 \%)$ were start sex before the age of 18 years and only $6(2.4 \%)$ of the students were start sex after 24 years. This has strong implication that early sexual initiation were observed in the study area and as well this has strong relation with reproductive health problems/risks. This finding has similarity with the study done in Harar, Ethiopia among youths $(8)$

From two hundred fifty Seven respondents who had ever sexual intercourse, $179(73.5 \%)$ of the students were not using contraceptive during the survey period. The reason for this might be; they were not easly access the contraceptive they want which consise with the qualitative findings. Most sexually active adolescents do not use modern contraception, this finding concise with the study done in USA (10) and this shows students may encounter through different risk.

From the total respondents currently using reproductive health services $59.1 \%$ were male and the rest $41.1 \%$ were females. This shows that males were more using RH service than females and this is becuase voluntary counseling and test and Condom is the two dominantly used $\mathrm{RH}$ components utilized by students in the study area and obviously Condom is utilized by male and this slightly increase the prevalence of males beside this, males start sexual intercourse early than females as observed from the study done in Harar, Ethiopia (8) but both groups did not exhastively using all the other reproductive health components.

The survey tries to show reproductive health service utilization by the year of study and from the finding forth year students were highly utilizing $(62.5 \%)$ than the other and followed by third year students $(59.7 \%)$, second year $(56 \%)$ and first year $(47.4 \%)$. As year of students increased the studets awareness to the environmental surounding and / or what services are available in the university (or out side) were well known and eager to utilize. But contrary to this 
fourth year students cover small sample proportional to the size; this is becuase some of forth year students were not available during data collection, they were at the attachement site out side the university and some college/institute had no forth year students.

\section{Conclusion and Recommendation}

Knowledge of reproductive health is low as shown from the findings, most of the respondent didn't knew $\mathrm{RH}$ components, reproductive health problems and didn't mentioned prevention methods. The finding revealed that there were a great number of respondents started sex before the age of 18 years and were not used reproductive health services during the survey period. So, Giving health education and increasing awareness for students on all reproductive health services components, problems and prevention method rather than just focusing on HIV/AIDS and condom beside,Students in need of contraceptive should be supported by availing adequate information on contraceptive method. The present survey showed there were high demand on reproductive health services among students in the study area and the university higher manager should establish youth friendly reproductive health services within the university. Further studies should be conducted in different part of the university set up and assessed from different community group's perspectives to come up with more representative findings.

\section{Acknowledgment}

The authors are grateful to colleagues of Ambo University, College of Medicine and Health Sciences and to the supervisor and data collectors who committed themselves throughout the study period. And Ambo University for funding the study. Finally, we would like to express our gratitude to all participants who voluntarily participated in the study.

\section{References}

[1] International Conference on Population Development(ICPD), 1994, Egypt, Cairo

[2] Simona R, John K. Knowledge, attitude and practices on Reproductive Health. African Journal of Reproductive Health. 2009;13(4).

[3] United Nation Fund for Population Agency(UNFPA). Overview of Adolescent Life. UNFPA; 2003.

[4] Family Health international. Intervention strategies that work for youth summary of Focus on youth adults, end of program Report, youth issues. 2002.

[5] EPHA. Task force Adolescent Reproductive Health Global and National initiatives and Lesson Learned. Addis Ababa, Ethiopia; 2003.

[6] Simona R, John K. Knowledge, Attitude and Practices Study on Reproductive Health Among Secondary School Students. African Journal of Reproductive Health. 2009;13(4).

[7] Gelane L, Lukman Y. A cross sectional study on prevalence of gender based violence in three high schools, Addis Ababa, Ethiopia. EJRH. 2008;2(1).

[8] Korra A, Haile M. Sexual behavior and level of awareness on reproductive health among youths :Evidence from Harar, Ethiopian. Ethiopian. J.Health Dev. 1999;13(2):107-13.

[9] Silesh G. Knowledge, attitude and practice of sexual coercion on young females in Nekemte town, west Ethiopia. ERHJ. $3(2)$.

[10] (ORC Macro Calverton Contraceptive Utilization Among Adolescents, Maryland, USA 2004 (http://www.measuredhs.com or by contacting:)

[11] Berhanu D, Nigatu R. Emergency Contraception among Female Students of Haramaya University, Ethiopia. Haramaya; 2004.

[12] Family Health International Youth Net. Family planning and AIDS-prevention activities. 2004. 